\title{
Research Paper: Effect of Navayesh Parent-Based Comprehensive Rehabilitation Program on the Development of Early Language and Communication Skills in Deaf Children Aged 0-2 Years
}

\author{
Saeid Hassanzadeh ${ }^{1},{ }^{*}$ Fatemeh Nikkhoo ${ }^{1}$ \\ 1. Department of Psychology and Education of Exceptional Children, Faculty of Psychology and Education, University of Tehran, Tehran, Iran.
}

(E) Hasanzadeh S, Nikkhoo F. [Efficiency of Navayesh Parent-Based Comprehensive Rehabilitation Program on Development of Early Language and Communication Skills of Deaf Children Aged 0-2 Years (Persian)]. Journal of Rehabilitation. 2017; 17(4):326-337. http://dx.doi.org/ 10.21859/jrehab-1704326

Received: 2 Jul. 2016 Accepted: 5 Oct. 2016

Keywords:

Parent-based comprehensive rehabilitation program, Communication skills, Language skills, Deaf children

\section{A B STR ACT}

Objective Early diagnosis and coherent rehabilitation programs play a key role in improving receptive and expressive language and communicational skills of deaf children. Communication with their parents could influence the development of languages and communication skills in these children. It is important to ensure parental involvement in the rehabilitation of deaf children as parent-therapists show the necessity for the provision of a comprehensive family-centered rehabilitation program along with the diagnosis of hearing loss and audiological and etiological evaluations.

Materials \& Methods This is an experimental study, with pre-test and post-test design. Sixty-two 0-2 years-old deaf children (30 girls and 32 boys), who either had undergone cochlear implant surgery or were candidates for cochlear implant surgery and had medical records at the Cochlear Implant Center in the Rasul Akram Hospital, were selected using purposive sampling. The subjects were then randomly divided into two groups (experimental and control groups). The subjects of the experimental group received the Navayesh parent-based comprehensive rehabilitation program in 18 group and individual sessions (6 group sessions and 12 individual sessions). To investigate early language and communication skills, the Ages and Stages Questionnaires, third edition, and the Communication and Symbolic Behavior Scales Developmental Profile were used. In addition, the Univariate and Multivariate Analysis of Covariance (MANCOVA) was used for the analysis of data.

Results The findings of this study demonstrated that post-test average scores in communication skills increased in the experimental group compared to the control group with respect to pre-test (43.33). In addition, the MANCOVA results suggested that Navayesh comprehensive rehabilitation program was effective in increasing the scores in the areas of communication skills, expressive language, and symbolic behavior $(P<0.001)$.

Conclusion The results are indicative of the effect of the Navayesh parent-based comprehensive rehabilitation program on the development of early language and communication skills of deaf children. Therefore, it is recommended that this program should be used at rehabilitation centers for deaf children, aiming at training parents as the primary therapists of deaf children.

\section{* Corresponding Author:}




\title{
اثربخشى برنامه جامع توانبخشى والدمحور نوايش بر رشد مهارتهاى ارتباطى اوليه و زبانى كودكان ناشنواي + تام ب سال
}

\author{
سعيد حسنزاده'، "فاطمه نيكخو'
}

1- كروه روانشناسى و آموزش كودكان استثنايیى، دانشكده روانشناسى و علوم تربيتى، دانشعان تهران، تهران، ايران.

\begin{abstract}
(20)

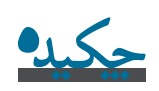

تاريخ دريافت: T|تير هوش

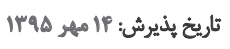

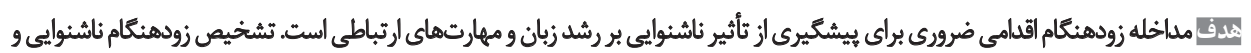

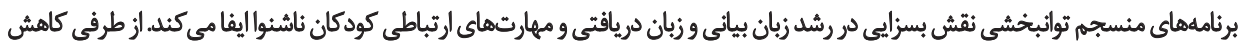

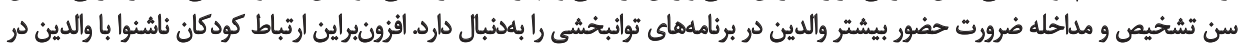

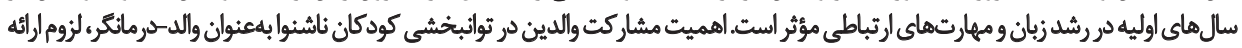

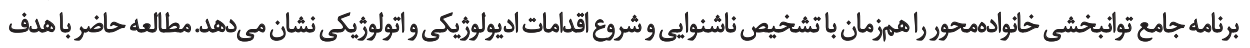

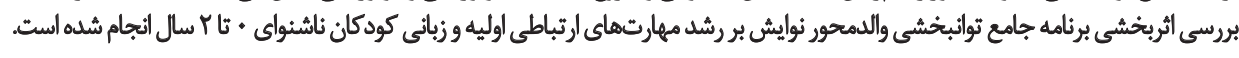

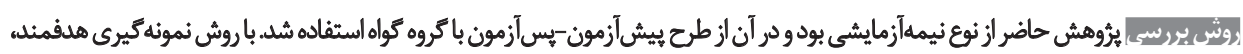

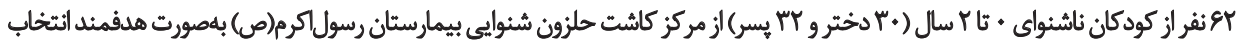

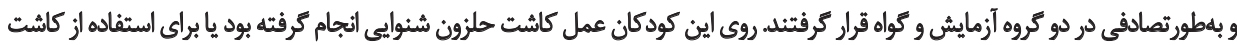

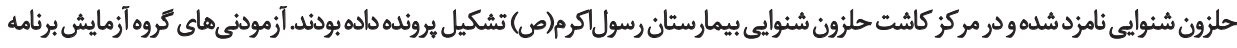

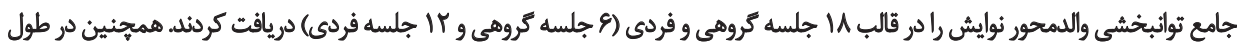

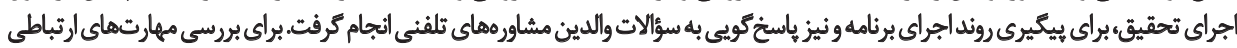

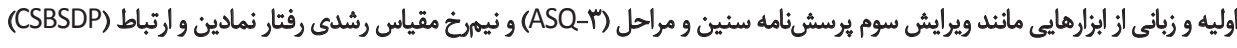

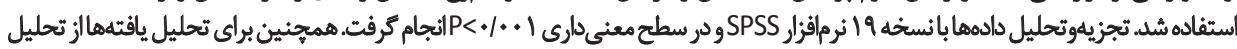

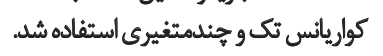

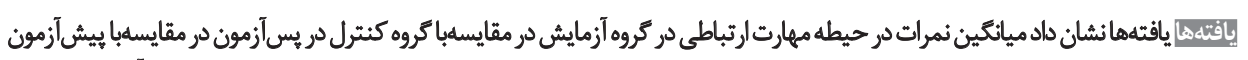

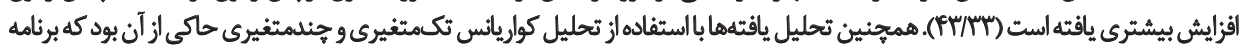

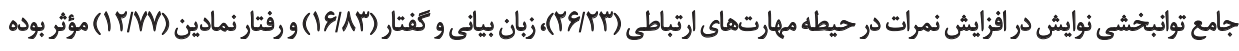

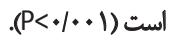

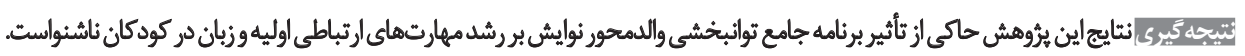

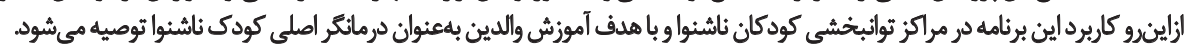

كليدوازٔهها:

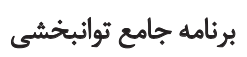

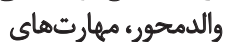

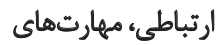
زبانى، كودكان ناشنوا
\end{abstract}

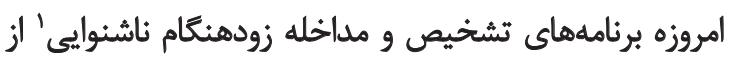

$\operatorname{datas}$

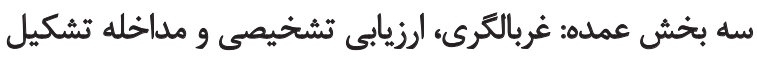

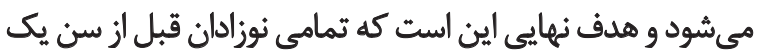

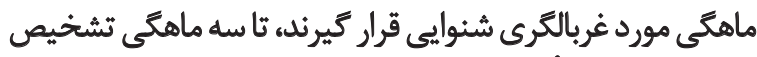

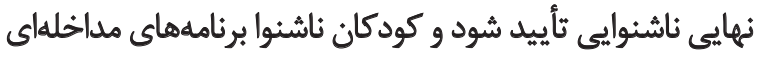

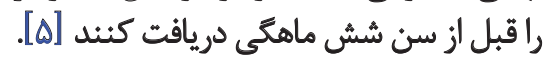

1. Early Hearing Detection and Intervention (EHDI)

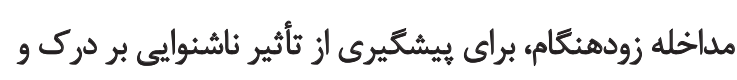

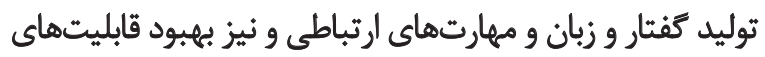

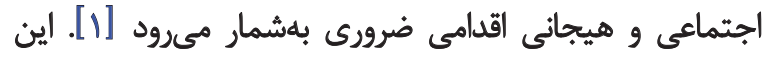

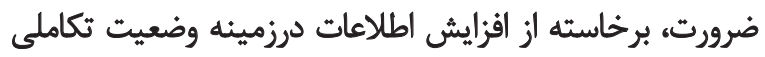

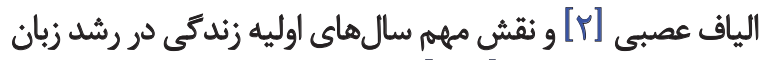

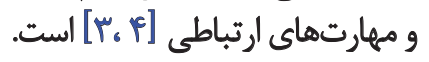

$$
\text { فاطمه نيكنو : نويسند مسئول: }
$$

نشائي: تهران، دانشعاه تهران، دانشكده روانشناسي و علوم تربيتي، كروه رواتشناسي و آموزش كودكان استثثنايى. تلفن: رايانامه: fnikkhoo@ut.ac.ir 
شنوايى بر مبناى اصول علمى و با تأكيد بر مداخله زودهنكام و

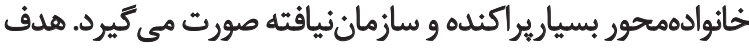

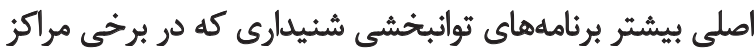

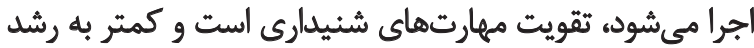

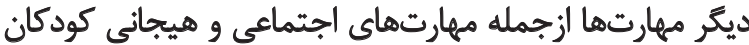

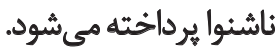

درحقيقت، مىتوان بهكونهاى برنامهايى رايج را بهعنوان

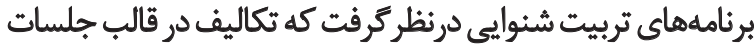

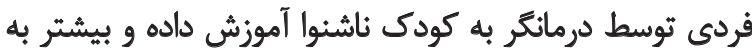

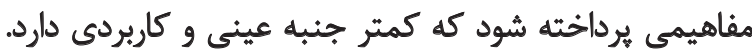

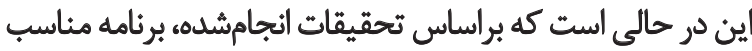

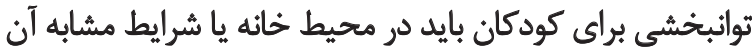

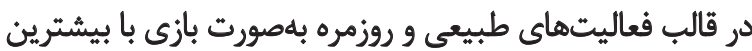

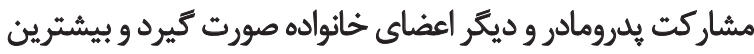

تعامل بين والدين و كودى ناشنوا فراهم شود [عاندان] ازسوى فيكر در بيشتر برنامههاى موجود، على برغم ثأكيد بر برازي

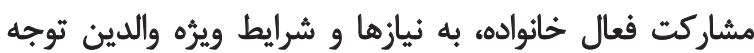

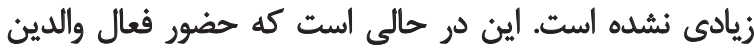

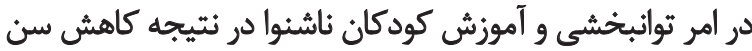

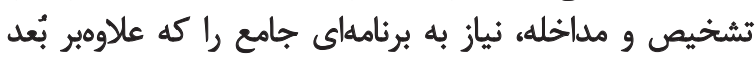

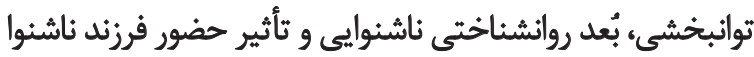

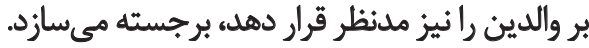
در ايران، ميزان شيوع ناشنوايى روزانه ا تا با مورد در هر هزار

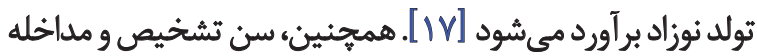

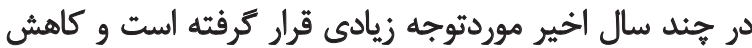

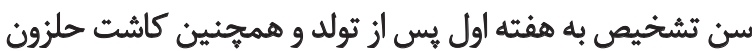

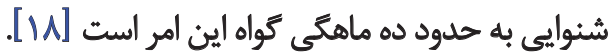

با توجه به اينكه بيشتر كودكان در سالهاي اوليه زندكّى زمان

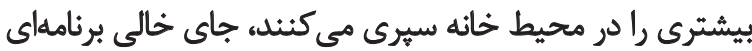

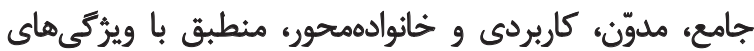

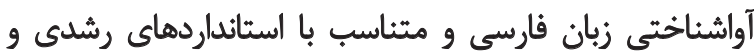

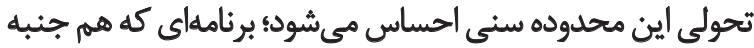

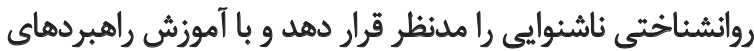

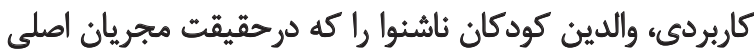

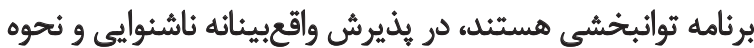

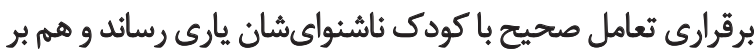

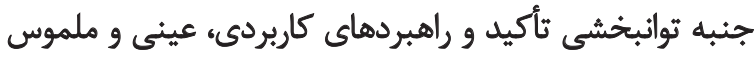

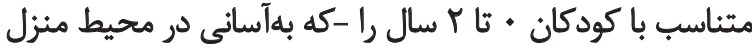

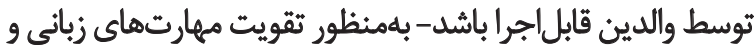

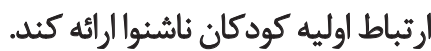

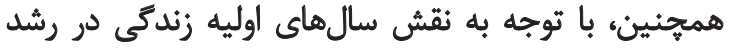
ديكر مهارتها ازجمله مهارتهاى اجتماعى و هيجانى، برنامه
ييشرفت فناورى در جهت تشخيص ناشنوايي در ساعتهاى

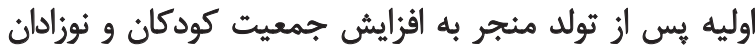

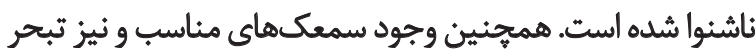

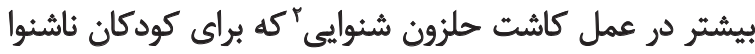

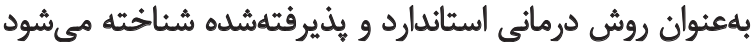

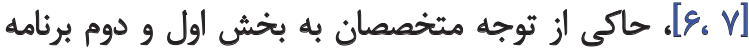
تشخيص و مداخله زودهنكًام است.

بالينوجود، تنها تشخيص بلموقع ناشنوايى و استفاده از سمعك

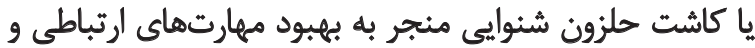

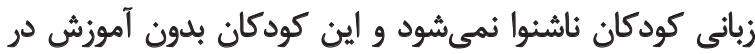

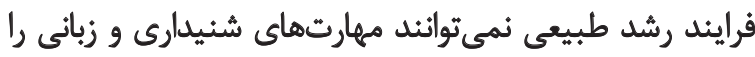

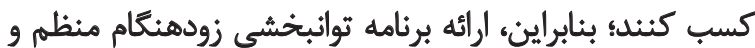

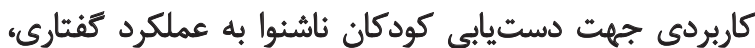

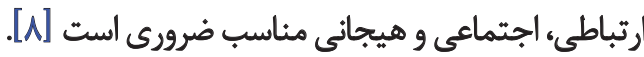

كاهش سن تشخيص و مداخله، ضرورت حضور بيشتر والدين

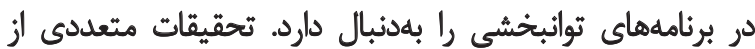

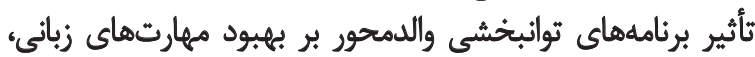

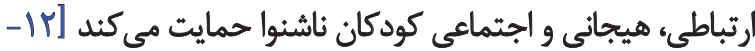

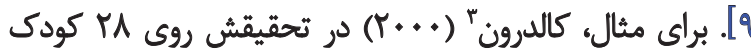

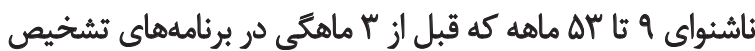

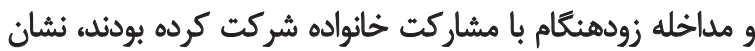

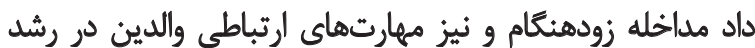

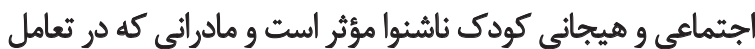

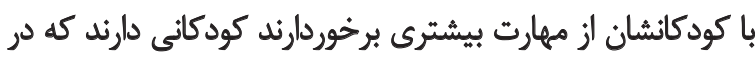

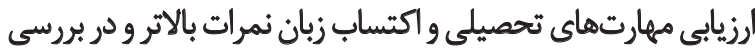

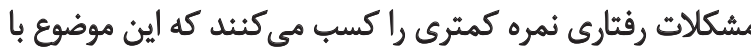

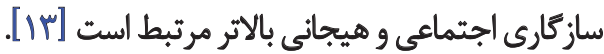

علاوهبراين، عملكرد بهتر كودكان ناشنواي نسل دومث (كودكان

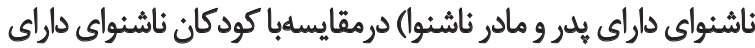

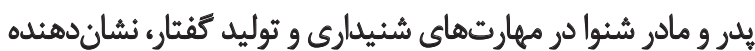

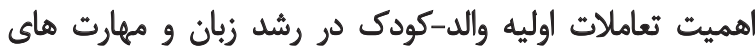

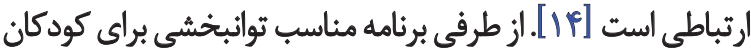

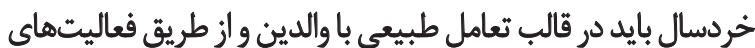

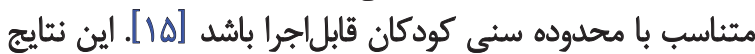

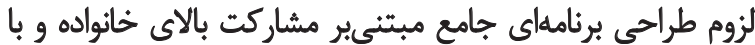

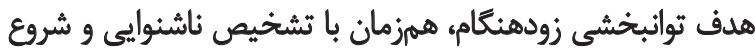

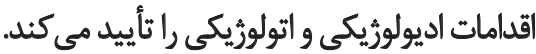

درحالحاضر، در ايران برنامه مكتوب، جامع و منسجم با محوريت اصلي خانواده وجود ندارد و آموزش و توانبخ جانشي نوين

2. Cochlear implant

3. Calderon

4. Second-generation deaf children 


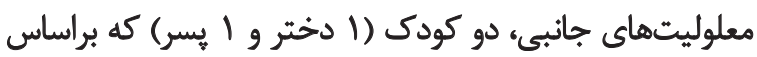

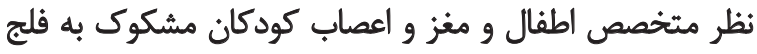

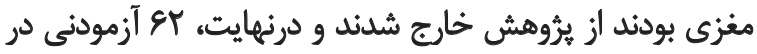

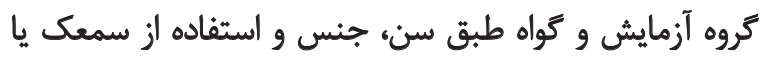

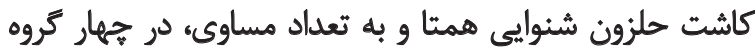

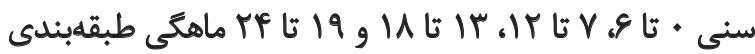

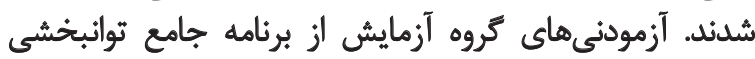

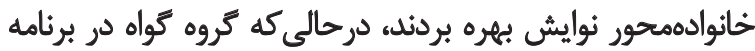
مداخلهاى موردنظر شركت نكرديند.

در اين مطالعه از ابزارهاى برسشنامهن سنين و مراحل نسخه

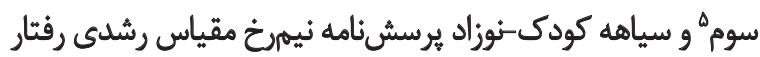

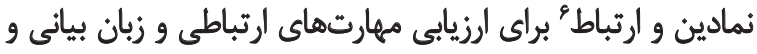

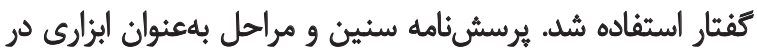

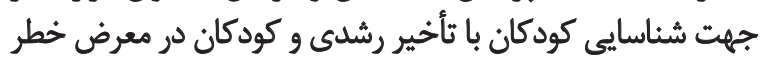

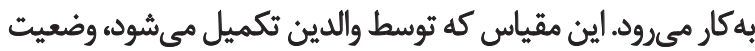

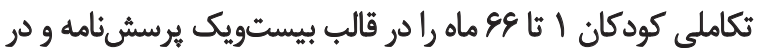

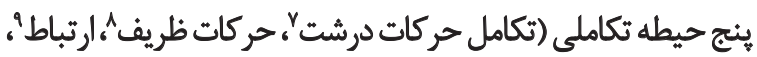

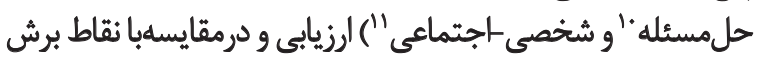

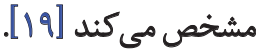

خردهمقياس مهارتهاى ارتباطى شامل سؤالاتى درزمينه

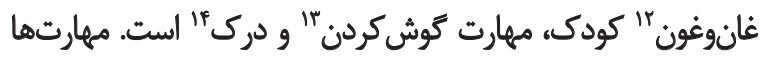

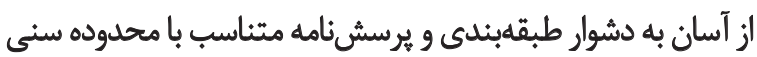

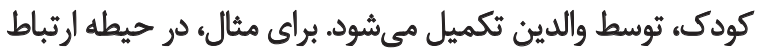

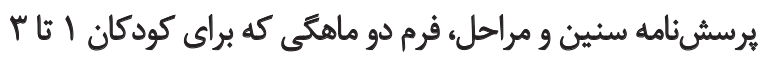

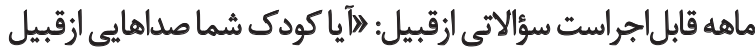

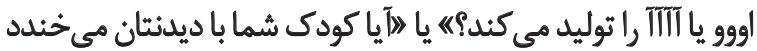

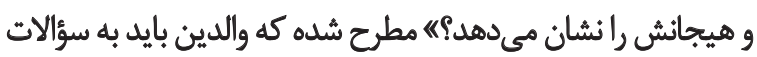
بلهورت البلى"، اهنوز نه" و "خير" ياسخ دهند.

در سال •l9V، تحقيقات صورت كرفته توسط بريكرها درزمينه

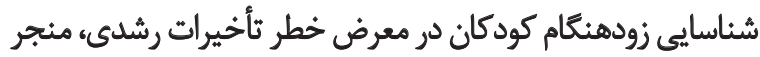

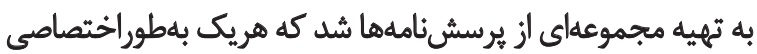

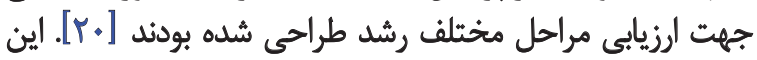

5. Ages and Stages Questionnaire (ASQ-III)

6. Communication and Symbolic Behavior Scale Developmental Profile (CSBSDP)/Infant Toddler Checklist

7. Gross motor

8. Fine motor

9. Communication

10. Problem solving

11. Personal-social

12. Babbling

13. Listening

14. Understanding

15. Bricker
جامع بايد به تسهيل رشد ديكر ابعاد نيز توجه داشته باشد. برنامه

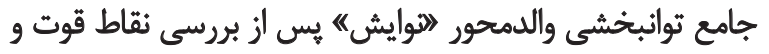

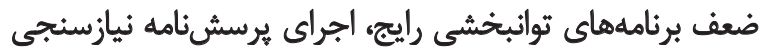

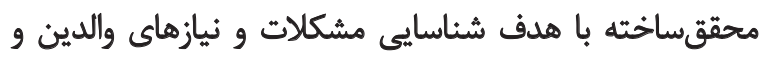

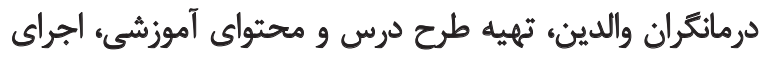

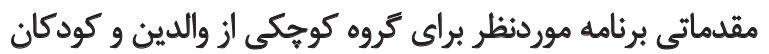

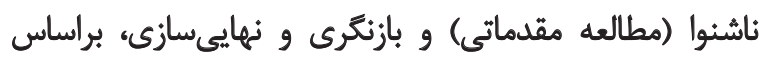

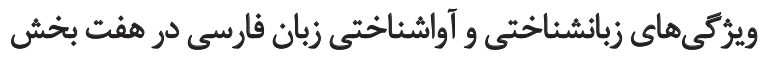
طراحى ترديده است.

اهداف كلى برنامه نوايش در جدول شماره إنان انشان داده

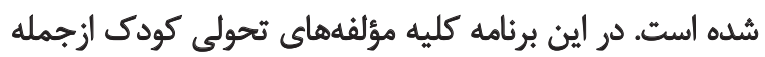

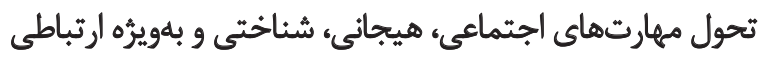

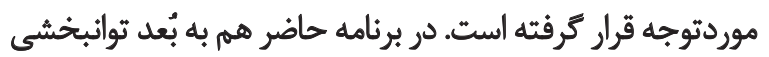

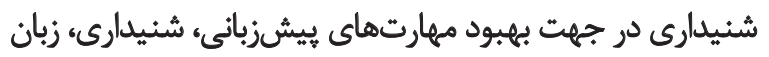

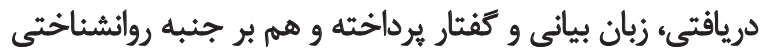

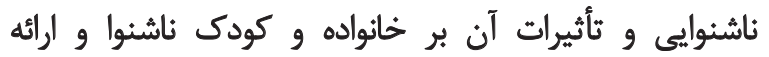

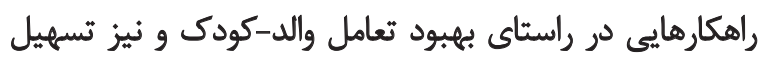
يذيرش واقعبينانه ناشنوايى تأكيد زيادى شده است

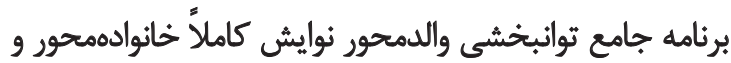

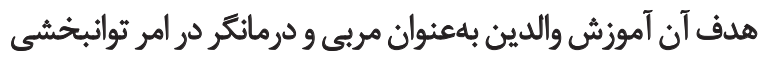

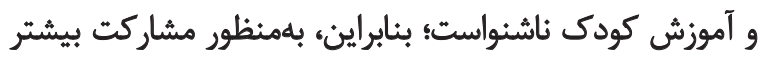

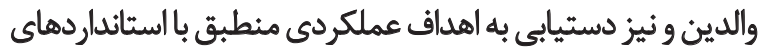

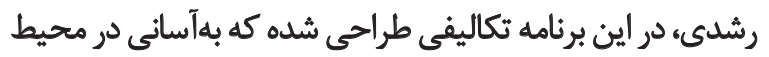

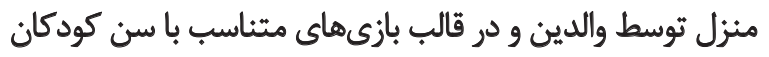

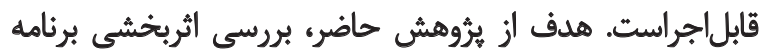

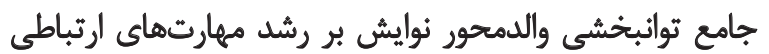
اوليه و زبانى است.

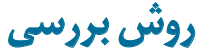

طرح مورداستفاده در اين يثروهش از نظر كردآ بروى دادهها

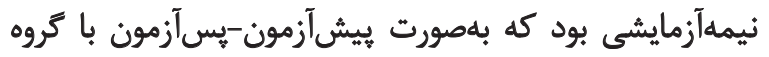

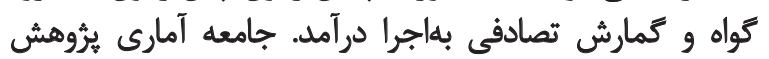

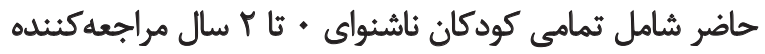

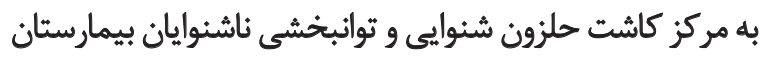

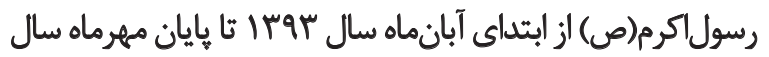

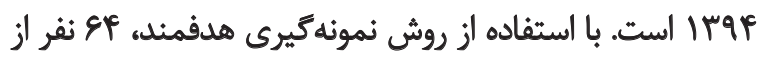

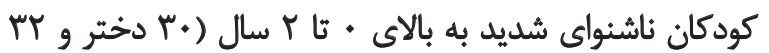

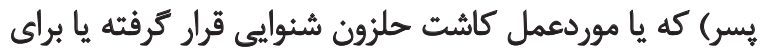

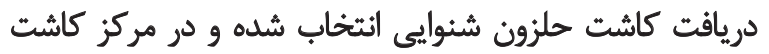

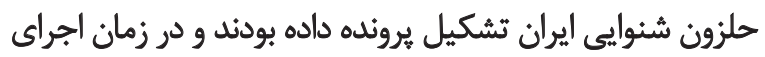

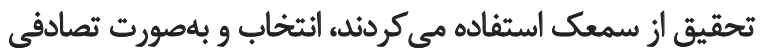
در دو كروه آزمايش و كواه قرار ترفيتند.

با توجه به يكى از ملاكهاى خروج از يُؤهش مبنىبر وجود 
ترجمه شده است. براي تعيين روايى محتوايى، از نظرات

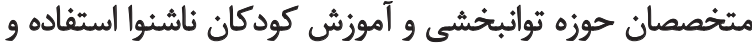

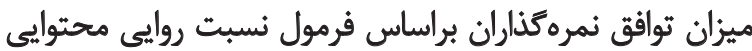
" محاسبه شد. "rf CVR=(n-N/T)

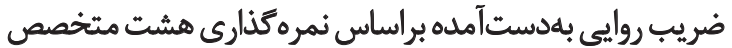

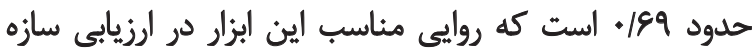

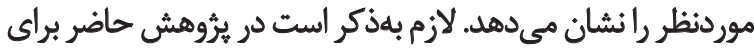

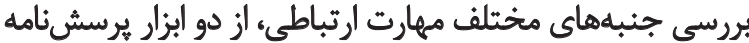

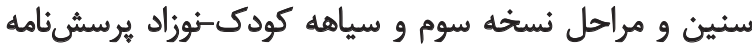
نيمرخ مقياس رشدى رفتار نمادين و ارتباط استفاده شده است.

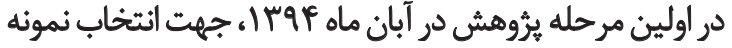

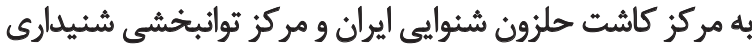

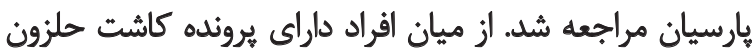

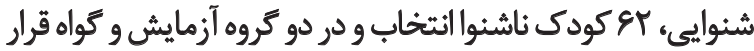

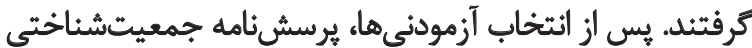

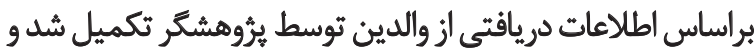

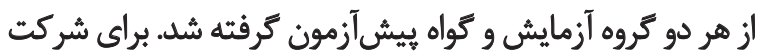

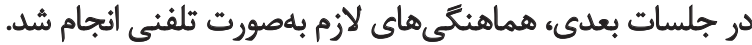

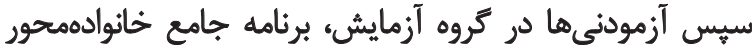

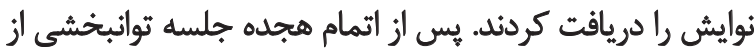

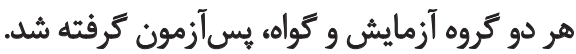

نحوه اجرا بدينترتيب بود كه مفاهيم مرتبط با بنج كام ام اول

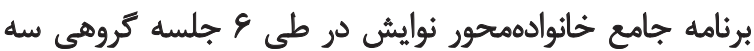

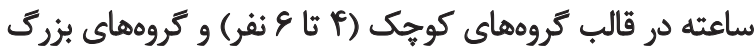

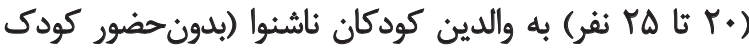

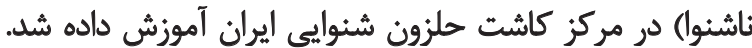

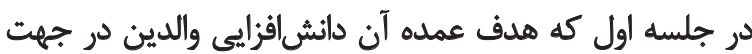

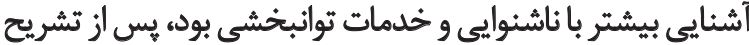

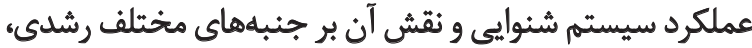

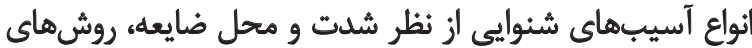

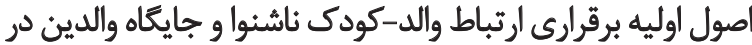
امر توانبخشى كودى ناشنوا تشريح شد.

طى جلسات دوم و سوم گروهى كه هدف عمده آنها آموزش

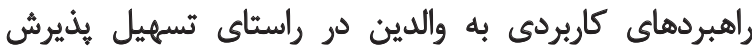

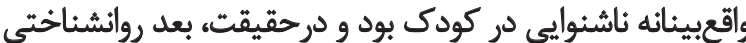

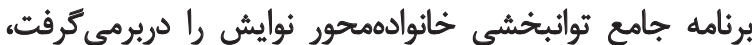

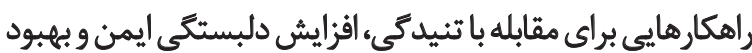
شيوه فرزنديرورى در اختيار والدين قرار ترفت.

در جلسات جهارم، يُنجم و ششم گروهى كه به وسايل كمك

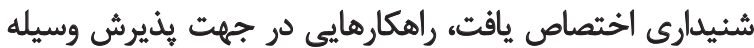

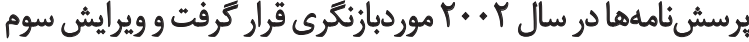

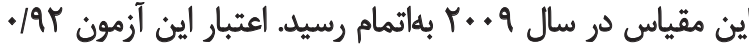

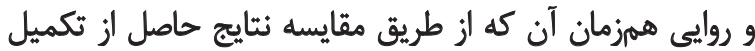

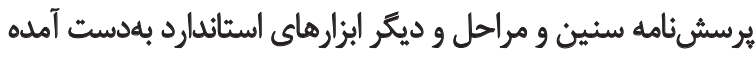

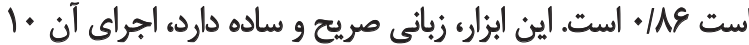

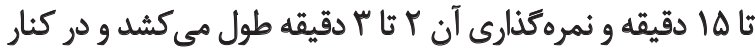

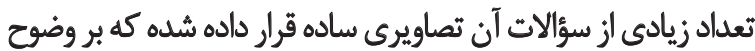
سؤالات مىافزيد و اجراي آن را آسان مى سكند. تعادي.

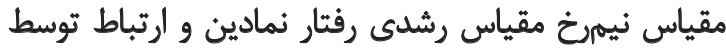

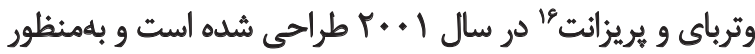

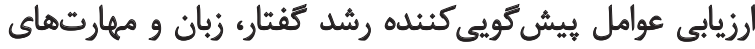

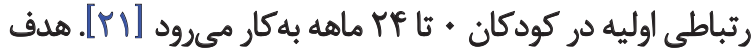

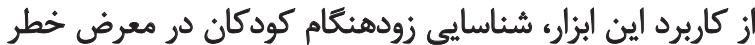

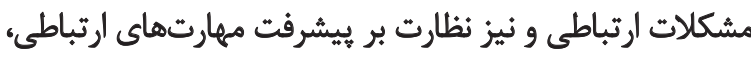

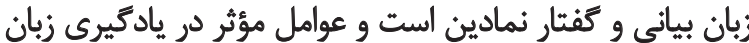

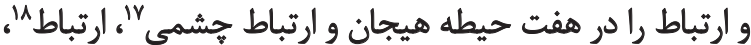

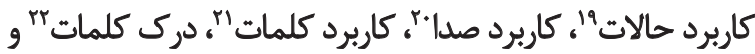

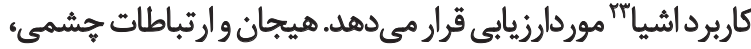

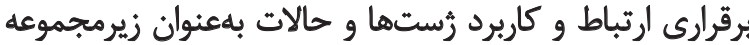

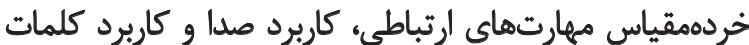

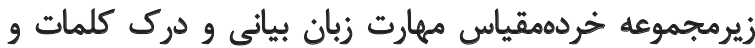
كاربرد اشيا زيرمجموعه خردهمقياس رفتار نمادين است زيتاني

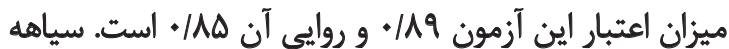

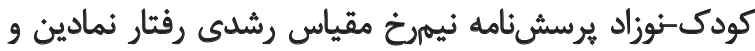

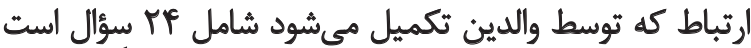

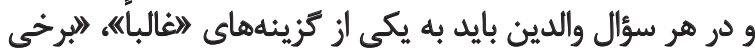

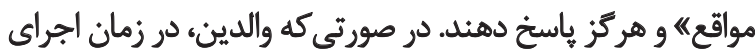

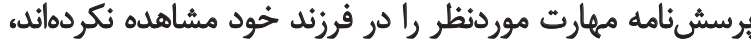

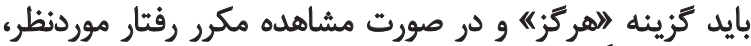

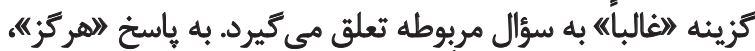

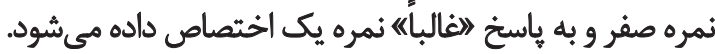
نمرات در سه خردهمقياس ارتباط، زبان بيانى و رفتار نمادين

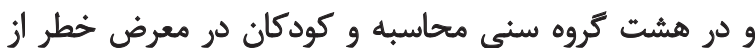

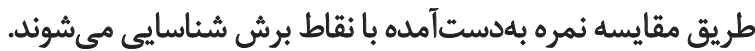

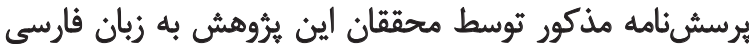

16. Wetherby and Prizant

17. Emotion a,d eye gaze

18. Communication

19. Use of gesture

20. Use of sounds

21. Use of words

22. Understanding of words

23. Use of object 
زبان بياني و توليد كفتثار بود، بهمنظور اجرا در محيط خانه به أبه

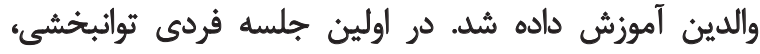

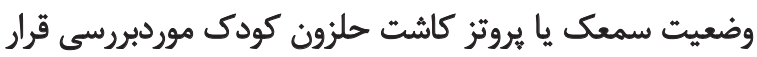

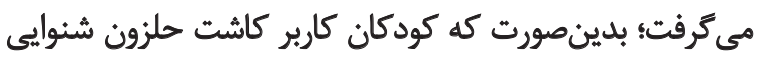

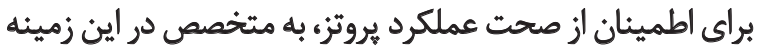

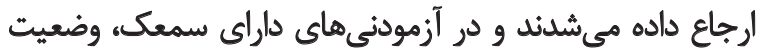

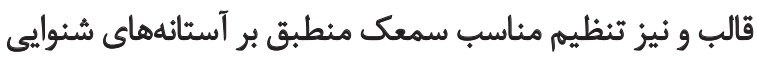
كودى، توسط ئروهشكر موردبر بنى قرار مى كرفت. نحوهاجرادر جلسات فردى توانبخشى بدينشكل بود كه ابتدادر

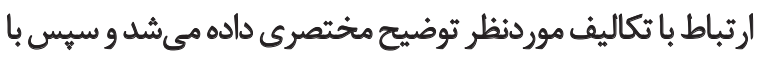
توجه به نقش الكوسازى در يادكيرى مفاهيه و نيز آشنايى والدين بادين

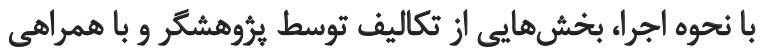

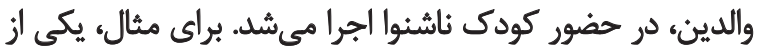

كمك شنوايى در كودى ناشنواء نحوه استفاده از سمعك يا بروتز

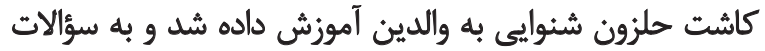

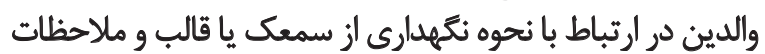

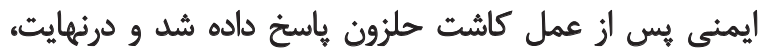
مطالب ارائهشده در جلسات يیشين، جمعبندى و ومرور شد. باممنظور تفهيم بيشتر مطالب كفتهشده، طى جلسات كروهى

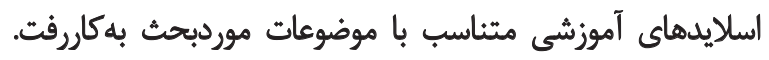

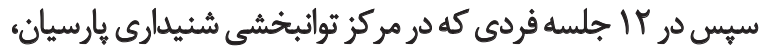

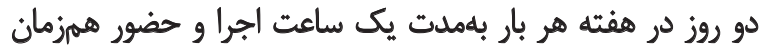

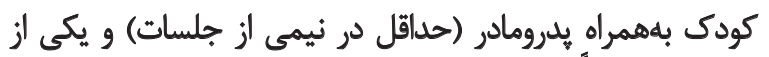

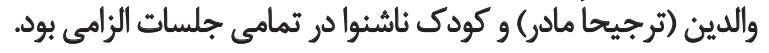
كامهاى ششم و هفتم برنامه كه شامل تكاليفى در راستاى

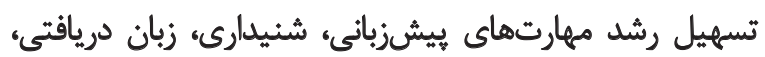

جدول ا. كامهاي برنامه جامع توانبخشي والدمحور نوايش.

\begin{tabular}{|c|c|c|}
\hline اهداف & كامها & \\
\hline 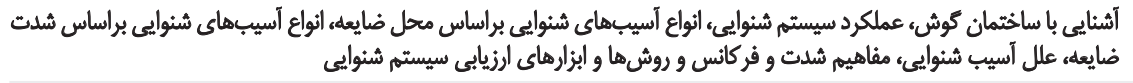 & سيستم شُؤوايع واثواع آسيبهايى & 1 \\
\hline 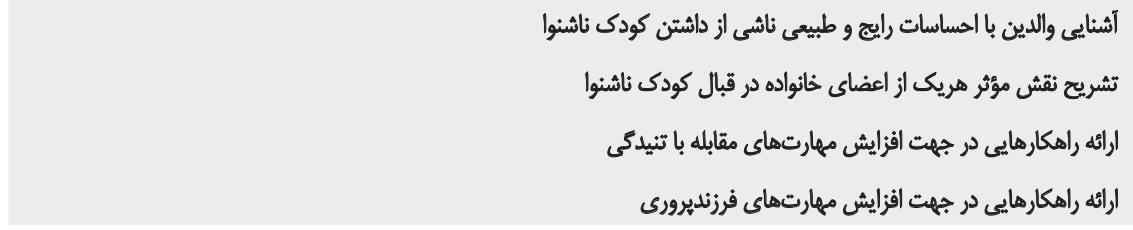 & تنيدكى روانى واللدين و راهبردهاى & r \\
\hline 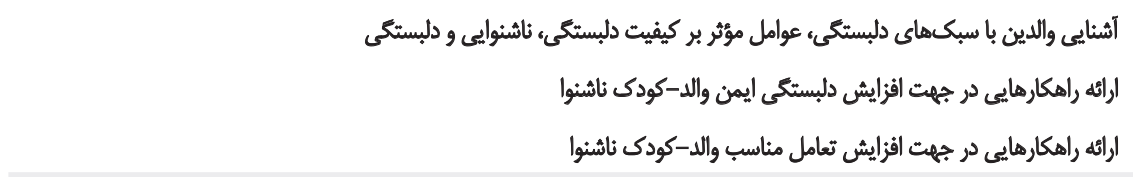 & سبكهائ دلبستكى و تعامل & $r$ \\
\hline 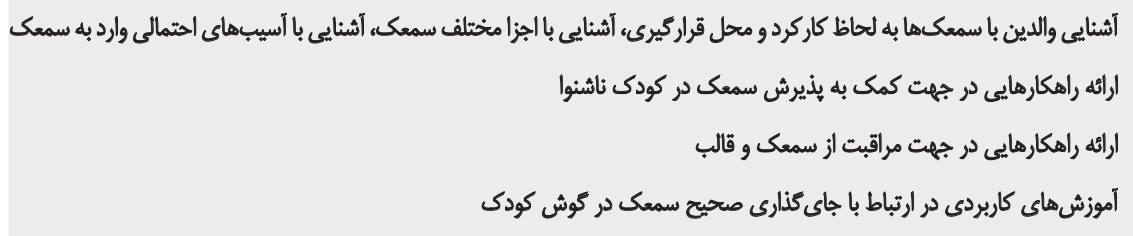 & سمعى & $f$ \\
\hline 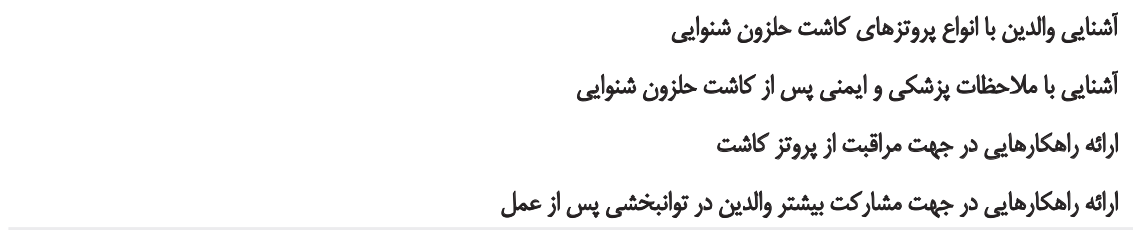 & كاشت حلزون شتوائ & $\Delta$ \\
\hline 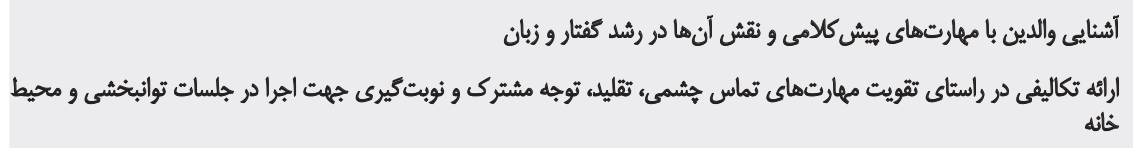 & ههارتهاى ييش كلامى & 8 \\
\hline 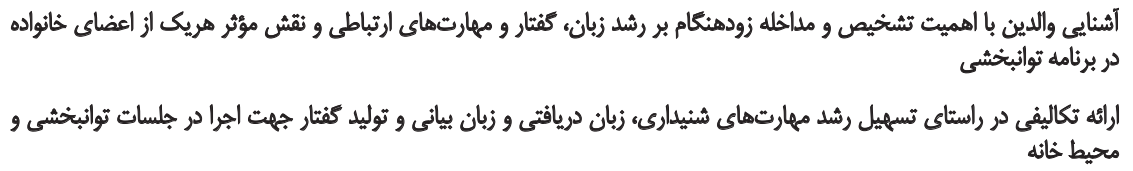 & توانبِتشى شُنيدارى & $v$ \\
\hline
\end{tabular}

توانبخننى 
در كروه آزمايش در بيشآزمون (VIT) بيش (G/FV)

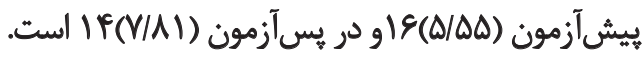
علاوهبراين، ويُّكى هاي توصيفى (ميانكين و انحراف معيار)

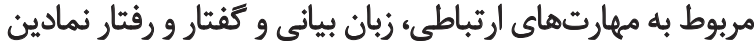

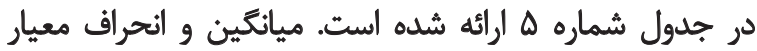

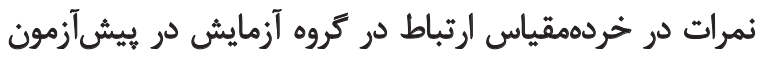
(F/TV(I/NT)

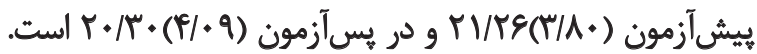

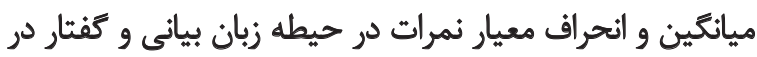
كروه آزمايش در بيش وآزمون (I/F)

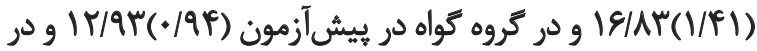

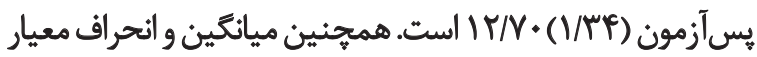

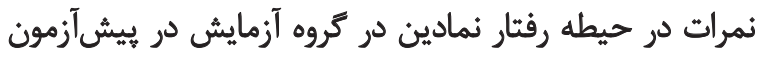

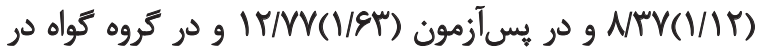

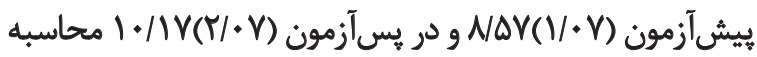
شده است.

براى بررسى اثر بخشى برنامه توانبخشى نوايش بر بهبوديود

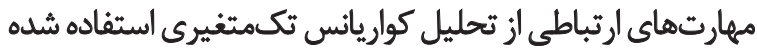

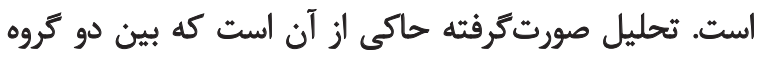

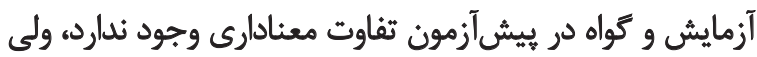

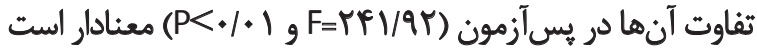

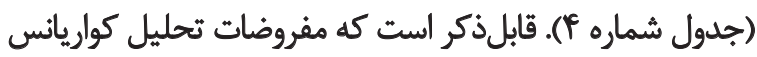

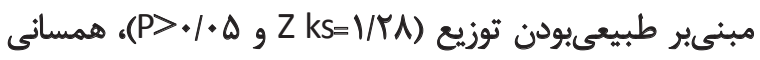

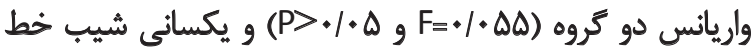
ركرسيونى براى دو كروه برقرار بوده است.

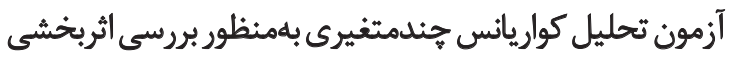

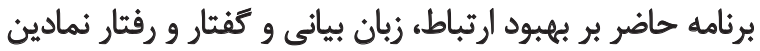

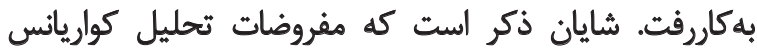

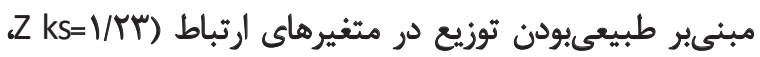

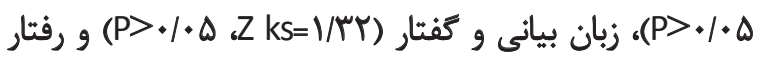

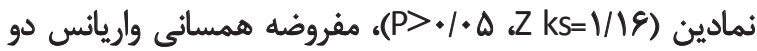

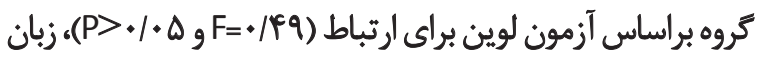

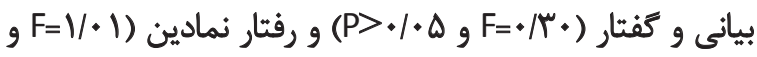

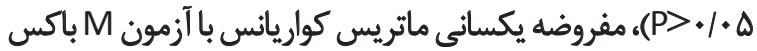
(P>./. Q و F=V/AT) كروه برقرار بوده است.

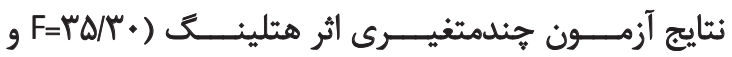

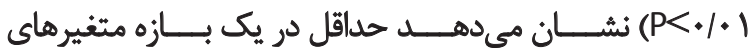

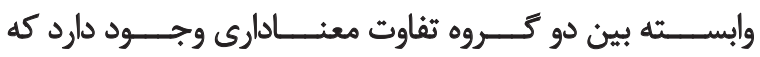

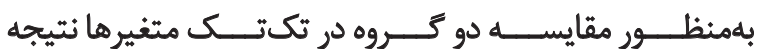

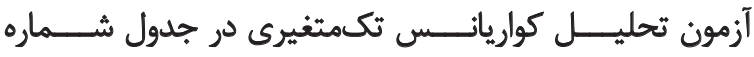

تكاليف كام ششم برنامه جامع توانبخشى خانوادهمحور نوايش؛

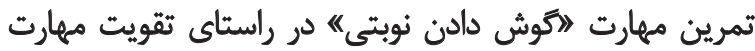

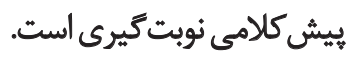

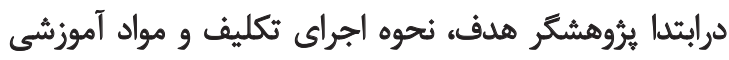

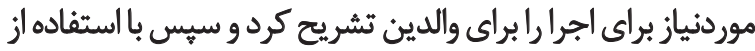

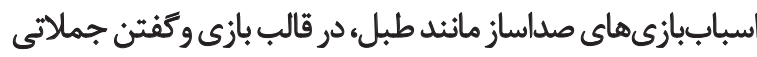

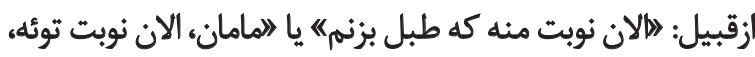

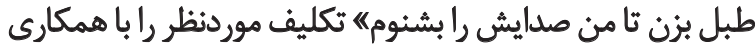

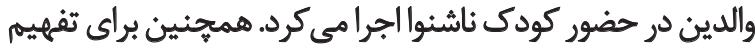

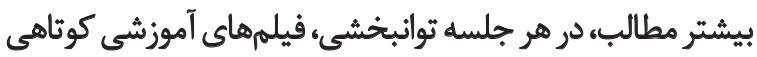

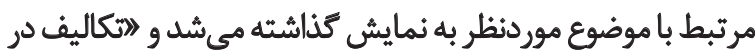
منزل " بهصورت مكتوب در اختيار والدين قرار مى مُرفت.

در شروع هر جلسه توانبخشى نيز مطالب ارائهشه در جلسات

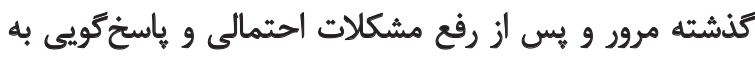

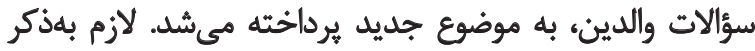

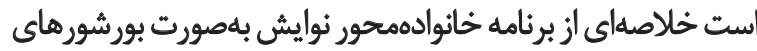

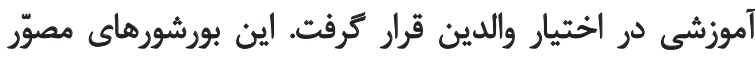

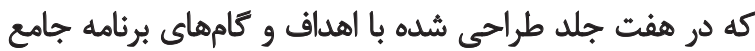

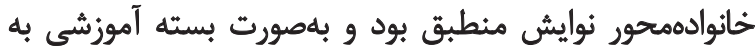

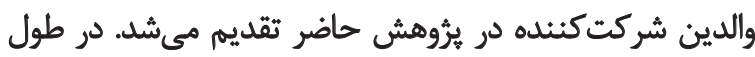

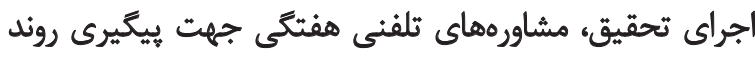

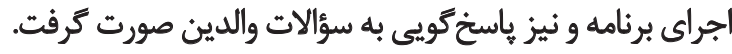
براى تحليل آمارى دادهها، شاخصهائ آمار توصيفي (ميانكين

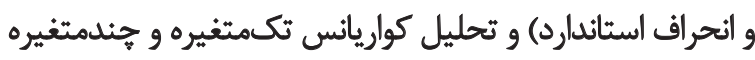

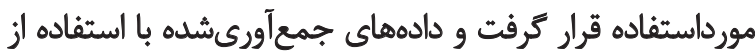

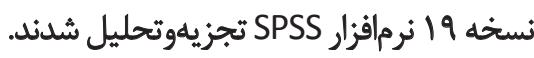

لازم بهذكر است قبل از شروع جلسات بهمنظور رعايت نكات

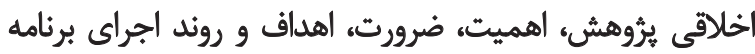

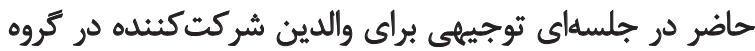

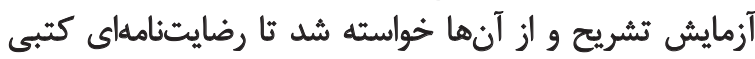

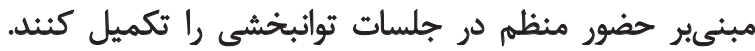

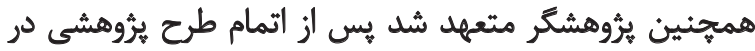

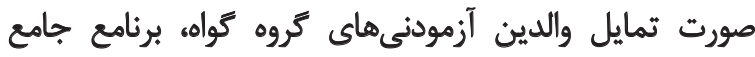

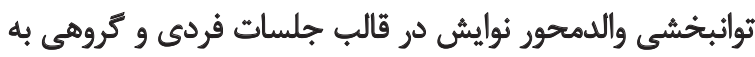

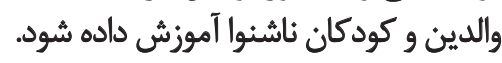

ياقتهذها

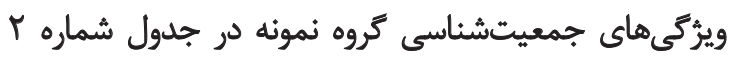

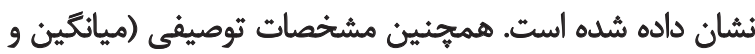

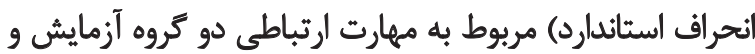

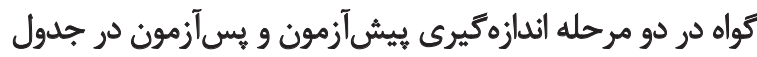

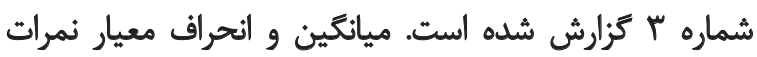


جدول T. ويثَّى هاي جمعيتشُناختى كروه نمونه (N=9T).

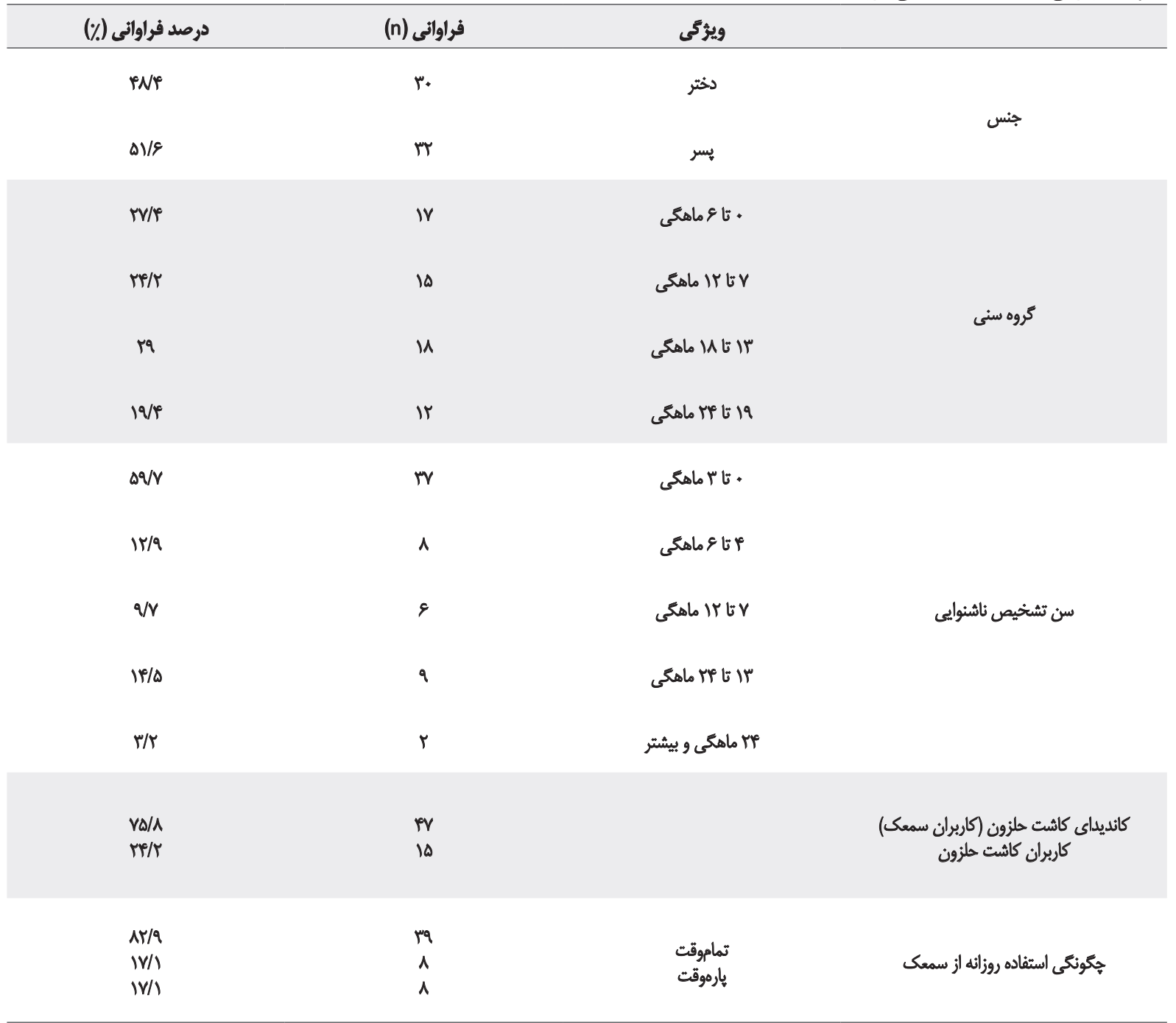

توانبخننى

جدول ". مشخصات توصيفى (ميانكين و انحراف استائدارد) مهارت ارتباطى.

\begin{tabular}{|c|c|c|c|c|}
\hline \multicolumn{2}{|c|}{ هس أزمون } & \multicolumn{2}{|c|}{ بيش آزمون } & \multirow[b]{2}{*}{ تروه } \\
\hline انعراف استاندارد & مياتكين & انحراف استائدارد & مياتكين & \\
\hline g/rV & $r / \pi r$ & $v / r q$ & T & آزمايش \\
\hline$V / A)$ & if & $\Delta / \Delta \Delta$ & 18 & كواه \\
\hline
\end{tabular}

توانبخنتى

جدول f. نتايج تحليل كواريانس مربوط به مهارت ارتباطى.

\begin{tabular}{|c|c|c|c|c|c|c|}
\hline اندازه اثر & $\mathbf{P}$ & $\mathbf{F}$ & MS & df & sS & مثغير \\
\hline .1 .8 & .1 .8 & $m / s \Delta$ & IVפ/ใด & 1 & IVq/9a & ييش آزهون \\
\hline \multirow[t]{2}{*}{$\cdot|A|$} & .10 .1 & Mri/ar & $1191 \% / 1$. & 1 & $1191 \% / 1$. & كروه \\
\hline & & & pqur & $\Delta V$ & $r A .8 M T$ & خطا \\
\hline
\end{tabular}


جدول هـ مشخصات توصيفى (ميائكين و انحراف استاندارد) مهارت ارتباطى، زبان بيانى و توليد كَفتار و رفتار نمادين.

\begin{tabular}{|c|c|c|c|c|c|}
\hline \multicolumn{2}{|c|}{ يسآزمون } & \multicolumn{2}{|c|}{ ييشآزمون } & \multirow{2}{*}{ كروه } & \multirow{2}{*}{ مثغير } \\
\hline اتحراف استاندارد & مياتكين & انحراف استاندارد & مياتكين & & \\
\hline \multirow[t]{2}{*}{$r / Y \wedge$} & TEMTI & $1 / N$ & $1 \% / r V$ & آزمايش & \\
\hline & & & & & ارتباط \\
\hline $4 / .9$ & $r \cdot r$. & $r / A_{0}$ & PITS & كواه & \\
\hline \multirow[t]{2}{*}{$\mid / m$} & IF/AT & $V \cdot r$ & WW/PT & أزمايش & \\
\hline & & & & & زبان ييانى و كُثتار \\
\hline $1 / \pi r$ & $i r / N$ &.$/ 94$ & $1 r / q T$ & كواه & \\
\hline \multirow[t]{2}{*}{$1 / 9$} & $I T / W$ & V/Tr & NTV & آزرمايش & \\
\hline & & & & & رفتار نمادين \\
\hline$r / * V$ & $1 . / 1 \mathrm{~V}$ & $v \cdot r$ & Nov & كواه & \\
\hline
\end{tabular}

توانبخننى

جدول \&. نتّايج تحليل كواريانس مربوط به خردمههارتهاي ارتباط؛ زبان بياني و كفتّار و رفتّار نمادين.

\begin{tabular}{|c|c|c|c|c|c|c|}
\hline اندازه اثر & $\mathbf{P}$ & $\mathbf{F}$ & MS & df & ss & متغير \\
\hline. & $.1 .+1$ & $T V / N$ & $M V / * A$ & 1 & $M V / \cdot A$ & الرثباط \\
\hline .189 & $.1 . .1$ & $r e / r A$ & $8 \& / \pi$ & 1 & 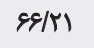 & زبان يبانيى و كمثتار \\
\hline.$/ 49$ &.$+\infty 1$ & $I r / I f$ & $\pi / A V$ & 1 & Tr/AV & رفتار نمادين \\
\hline
\end{tabular}

توانبخننى

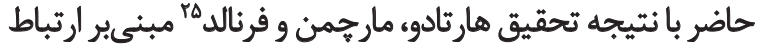

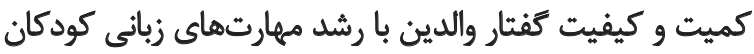

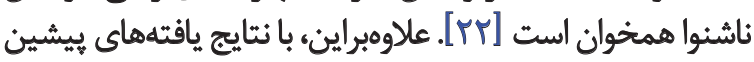

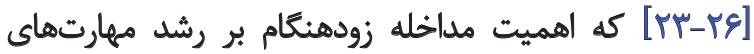

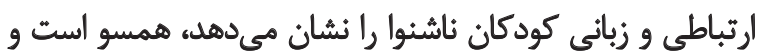
آنها را تأييد مي كند.

تحقيق انجامشده توسط تايت، نيكولويلوس و دريو (V) (Y)

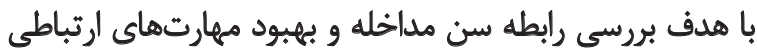

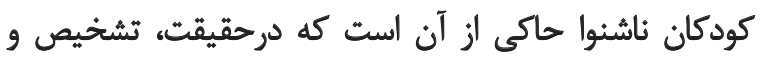

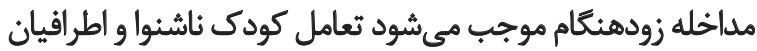

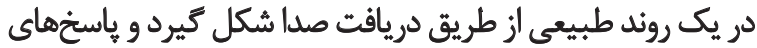

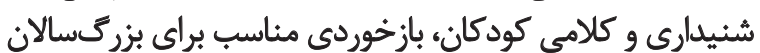

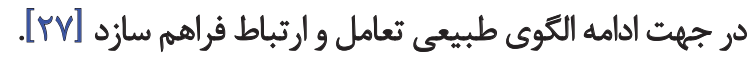
در برنامه توانبخشى نوايش هم به بُعد توانبخشى شنيدارى

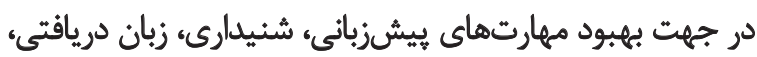

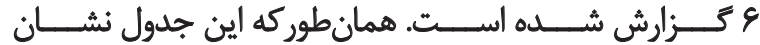

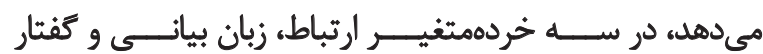

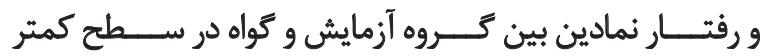

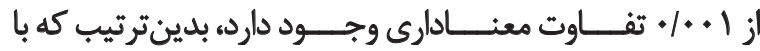

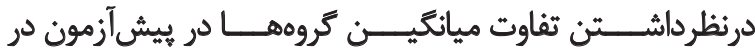

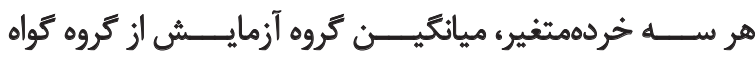

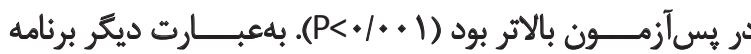

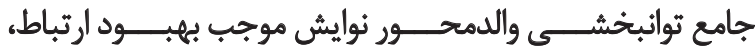

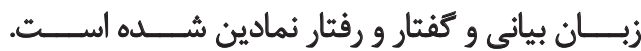

ب

هدف از هُروهش حاضر، بررسى اثربخشى برنامه جامع

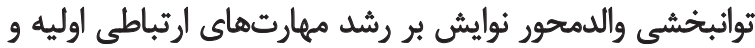

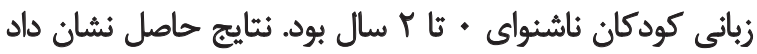

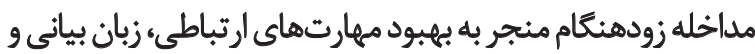

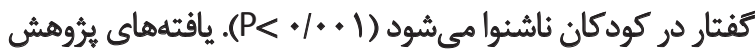




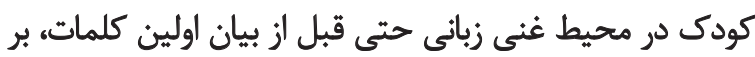

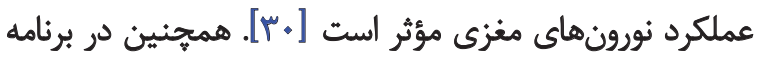

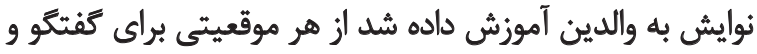

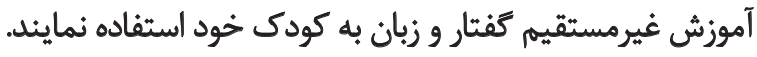

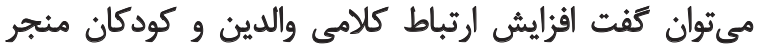

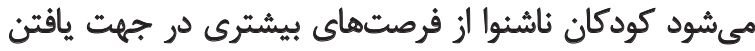

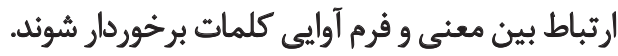

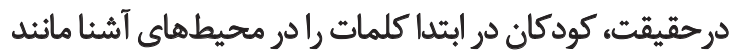

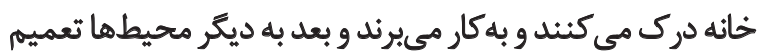

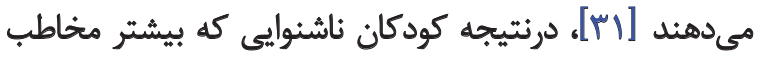

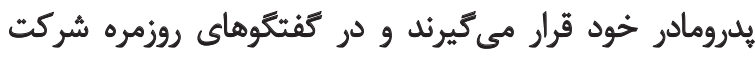

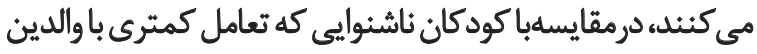
خود دارند، از رشد زبانى بالاترى برخوردارندان

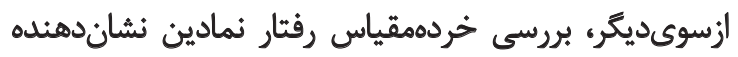

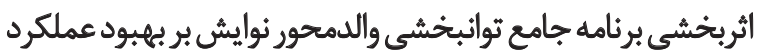

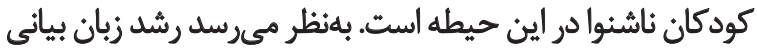

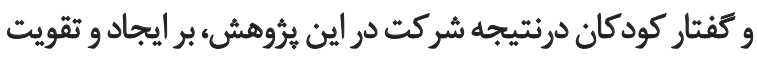

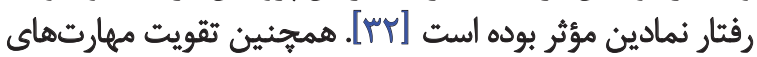

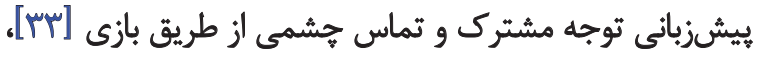

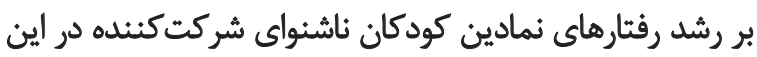

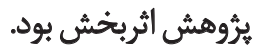

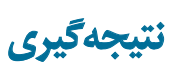

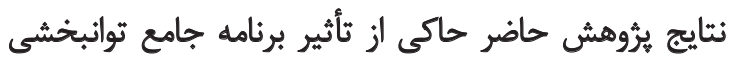

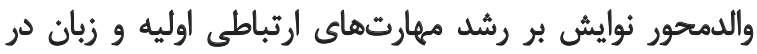

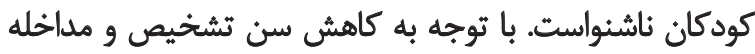

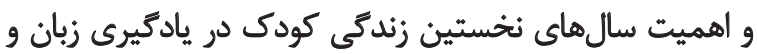

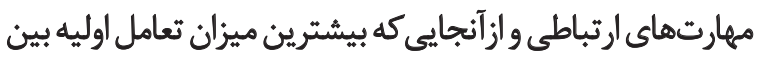

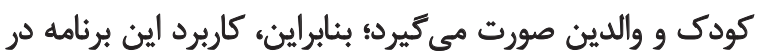

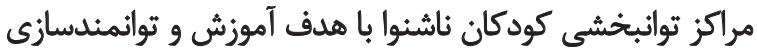

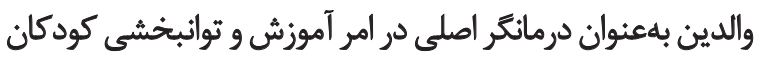
ناشنوا توصيه مي بشود.

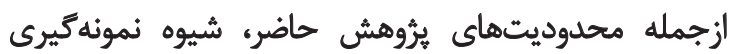

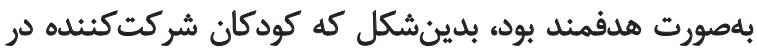

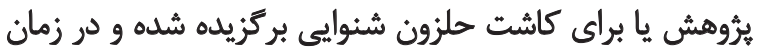

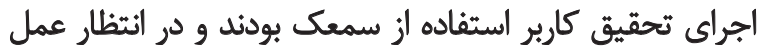

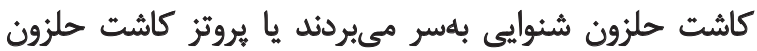

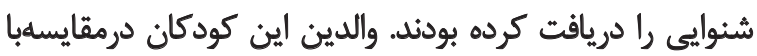

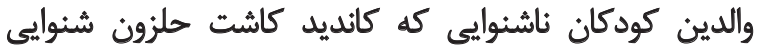

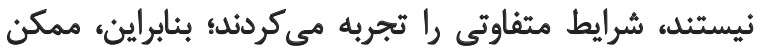

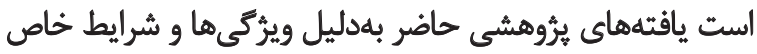

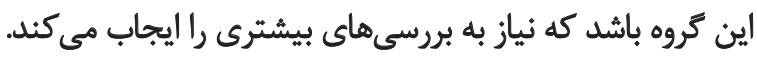

زبان بيانى و كفتار يرداخته و هم بر جنبه روانشناختي ناشنوايى زئي

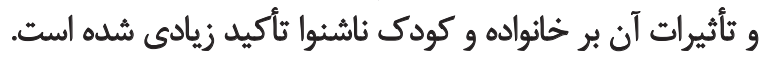

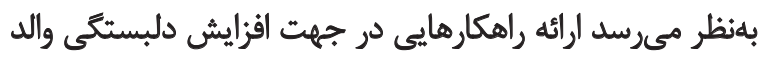

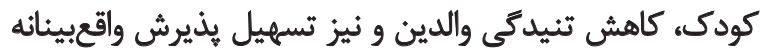

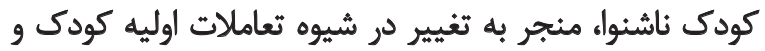

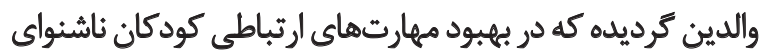

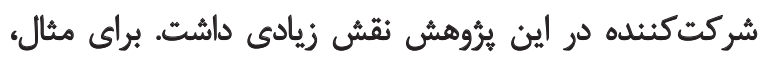

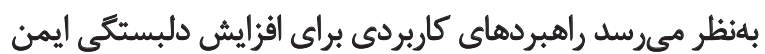

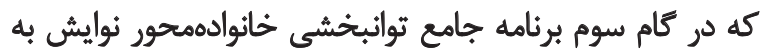

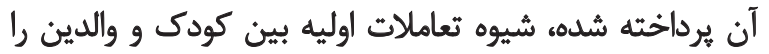

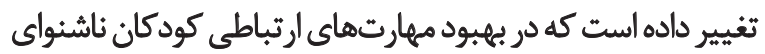

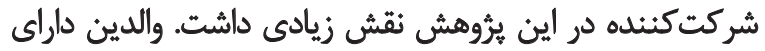

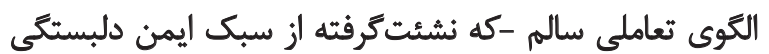

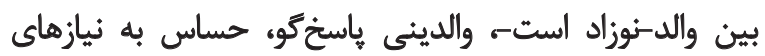

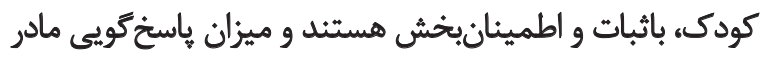

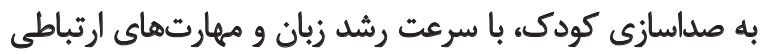

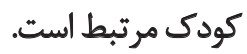

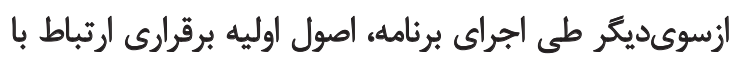

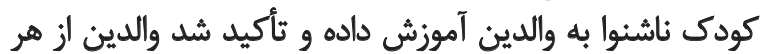

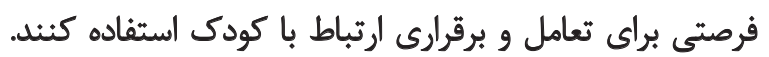

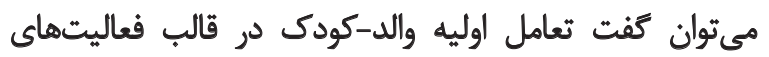

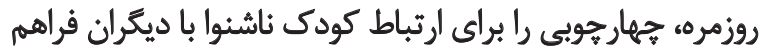

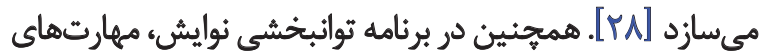

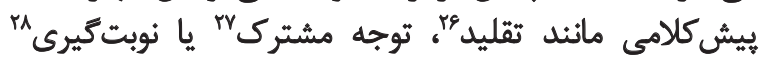

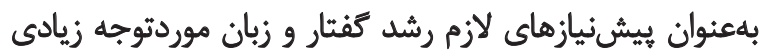

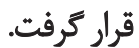

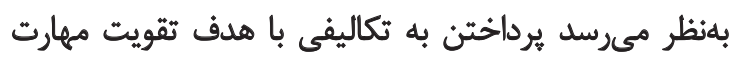

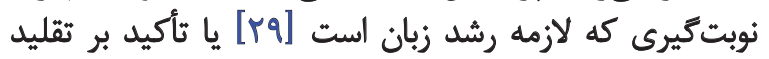

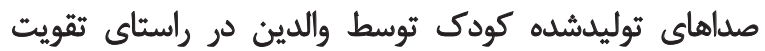

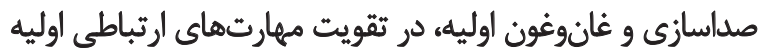

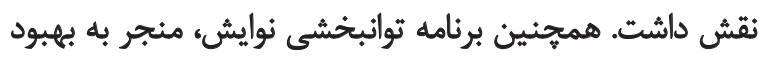

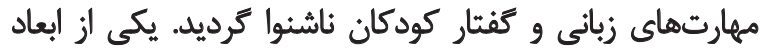

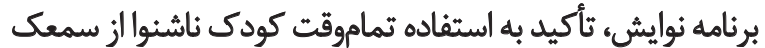

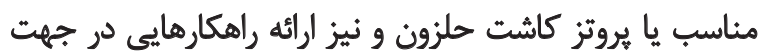

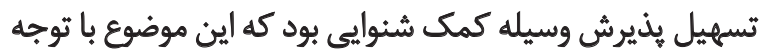

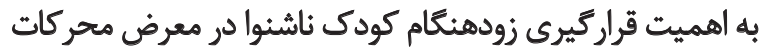

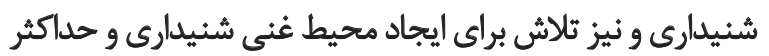
استفاده از باقى مانده شنوايى، قابل توجيح است. تحقيقات رفتارى و عصبشناختى نشان مىدهد قراركيرى

26. Imitation

27. Joint attention

28. Turn taking 


\section{References}

[1] Schorr E, Roth F. Quality of life for children with cochlear implants: perceived benefits and problems and the perception of single words and emotional sounds. Journal of Speech, Language \& Hearing Research. 2009; 52(1):141-52.

[2] Kuhl PK. Brain mechanisms in early language acquisition. Neuron. 2010; 67(5):713-27.

[3] Lenneberg E. Biological foundations of language. New York: John Wiley \& Sons; 1967.

[4] Jeddi Z, Jafari Z, Motasaddi Zarandy M. [The impact of cochlear implants and aural rehabilitation program on auditory skills of children with cochlear implant (Persian)]. Journal of Rehabilitation. 2013; 14(1):61-70.

[5] Paul P, White G. Hearing and deafness: an introduction for health and education professionals. Burlington: Jones \& Bartlett; 2011.

[6] Phillips L, Hassanzadeh S, Kosaner J, Martin J. Comparing auditory perception and speech production outcomes: non-language specific assessment of auditory perception and speech production in children with cochlear implants. Cochlear Implants International. 2009; 10(2):92-102.

[7] Ashoori M, Jalilabkenar S, Hasanzadeh S, PourmohamadrezaTajrishi M. [Speech Intelligibility in Children with Cochlear Implant, with Hearing Aids and Normal Hearing (Persian)]. Journal of Rehabilitation. 2013; 14(3):8-15.

[8] Baudonck N, Dhooge I, Haeseleer E, Van L. A comparison of the consonant production between Dutch children using cochlear implants and children using hearing aids. International Journal of Pediatric Otorhinolaryngology. 2010; 74(4):416-21.

[9] Sugaya A, Fukushima K, Kasai N, Kataoka Y, Maeda Y, Nagayasu $\mathrm{R}$, et al. Impact of early intervention on comprehensive language and academic achievement in Japanese hearing-impaired children with cochlear implants. International Journal of Pediatric Otorhinolaryngology. 2015; 79(12):2142-146.

[10] Wheeler A, Archbold S, Gregory S, Skipp A. Cochlear implants: The young people's perspective. Journal of Deaf Studies \& Deaf Education. 2007; 12(3):303-16

[11] Christa C, Meghana K, Deborah J. Enhancing parent-child communication and parental self-esteem with a video-feedback intervention: outcomes with prelingual deaf and hard of hearing children. Journal of Deaf Studies \& Deaf Education. 2015; 20(3):266-74.

[12] DesJardin JL. Assessing parental perceptions of self-efficacy and involvement in families of young children with hearing loss. Volta Review. 2003; 103(4):391-409.

[13] Calderon R. Parental involvement in deaf children's education programs as a predictor of child's language, early reading, and social-emotional development. Journal of Deaf Studies \& Deaf Education. 2000; 5(2):140-55.

[14] Hassanzadeh S. Outcomes of cochlear implantation in deaf children of deaf parents: Comparative study. Journal of Laryngology \& Otology. 2012; 126(10):989-94

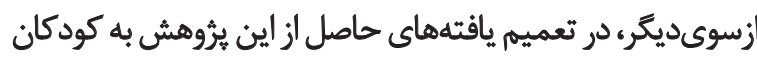

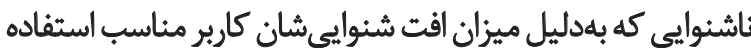

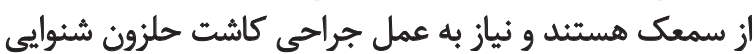
ندارند، بايد دقت بيشترى شود.

با توجه به اثربخشى برنامه جامع خانوادهمحور نوايش بر إنائ

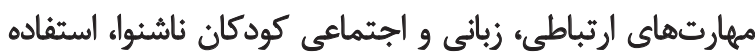

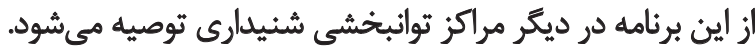

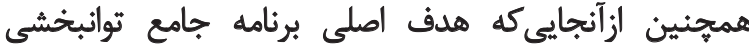

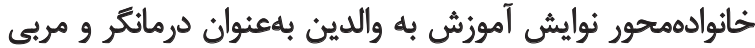

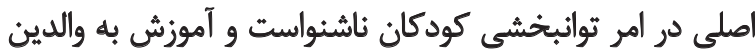

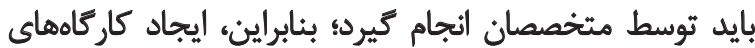

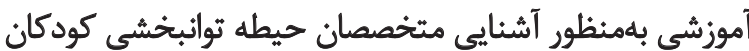

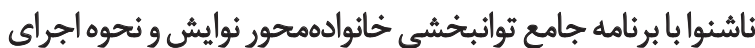

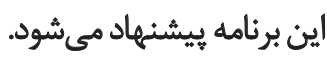

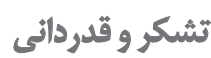

اين مقاله بركرفته از رساله دكترى نويسئده مسئول در رشته

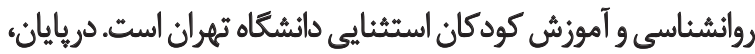

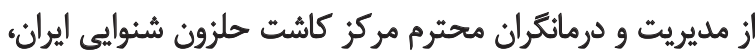

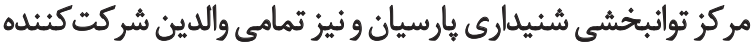

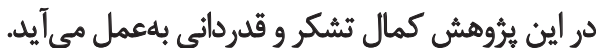


[15] Caudle B, Bentley H, Abaya J, Lin D. Cognitive outcomes and familial stress after cochlear implantation in deaf children with and without developmental delays. Otology \& Neurotology. 2012; 33(6):947-56.

[16] Macaulay C, Ford R. Family influences on the cognitive development of profoundly deaf children: exploring the effects of socioeconomic status and siblings. Journal of Deaf Studies \& Deaf Education. 2013, 18(2):245-62.

[17] Zamanpour M, Hatamizadeh N, Roshanak Vameghi R, Bakhshi E. [Assistive technology needs assessment from adolescent students with hearing loss and their parents, Ahvaz city-2013 (Persian)]. Journal of Rehabilitation. 2014; 15(3):42-53.

[18] Daneshi A, Hassanzadeh S. Cochlear implantation in prelingually deaf persons with additional disability. Journal of Laryngology \& Otology. 2007; 121(7):635-38.

[19] Schonhaut L, Armijo I, Alvers J, Cordero M. Validity of the ages and stages questionnaires in term and preterm infants. Pediatrics. 2013; 131(5):1468-474.

[20] Squires J, Bricker D. Ages \& stages questionnaires. $3^{\text {rd }}$ ed. Baltimore: Brookes Publishing; 2009.

[21] Wetherby A, Prizant B. Communication and symbolic behavior scales developmental profile- preliminary normed. Baltimore: Brookes Publishing; 2001.

[22] Hurtado N, Marchman VA, Fernald A. Does input influences uptake? Links between maternal talk, processing speed and vocabulary size in Spanish-learning children. Developmental Science. 2008; 11(6):31-39.

[23] Hassanzadeh S, Farhadi M, Daneshi A, Emamjomeh H. The effects of age on auditory speech perception development in cochlear-implanted prelingually deaf children. OtolaryngologyHead \& Neck Surgury. 2002; 126(5):524-27.

[24] Dettman S, Wall E, Dowell R. Communication outcomes for groups of children using cochlear implants enrolled in auditoryverbal, aural-oral, and bilingual-bicultural early intervention programs. Otology \& Neurotology. 2013; 34(3):451-59.

[25] Wieringen AV, Wouters J. What can we expect of normally-developing children implanted at a young age with respect to their auditory, linguistic and cognitive skills? Hearing Research. 2015; 322:171-79. doi: 10.1016/j.heares.2014.09.002

[26] Netten AP, Rieffe C, Theunissen SC, Soede W, Dirks E, Korver $\mathrm{AM}$, et al. Early identification: language skills and social functioning in deaf and hard of hearing preschool children. International Journal of Pediatric Otorhinolaryngology. 2015; 79(12):2221-226.

[27] Tait L, De Raeve L, Nikolopoulos T. Deaf children with cochlear implants before the age of 1 year: comparison of preverbal communication with normally hearing children. International Journal of Pediatric Otorhinolaryngology. 2007; 71(10):1605-611.

[28] Reichmuth K, Embacher A, Matulat P. Responsive parenting intervention after identification of hearing loss by Universal Newborn Hearing Screening: the concept of the Muenster Parental Program. International Journal of Pediatric Otorhinolaryngology. 2013; 77(12):2030-039.

[29] Hassanzadeh S. [Psychology and education of deaf children (Persian)]. Tehran: Samt Publishing; 2009.
[30] Patrica K, Kuhl K. Brain mechanism in early language acquisition. Neuron. 2010; 67(5):713-27.

[31] Not P, Cowan R, Brown M, Wigglesworth G. Assessment of language skills in young children with profound hearing loss under two years of age. Journal of Deaf Studies \& Deaf Education. 2003; 8(4):401-21.

[32] Loots G, Devise I. The use of visual tactile communication strategies by deaf and hearing fathers and mothers of deaf infants. Journal of Deaf Studies \& Deaf Education. 2003; 8(1):3142.

[33] Loots G, Devise I, Jacquet W. The impact of visual communication on the intersubjective development of early parent-child interaction with 18 to 24 month old deaf toddlers. Journal of Deaf Studies \& Deaf Education. 2005; 10(4):357-75.

[34] Ashoori M, Jalilabkenar S, Hasanzadeh S, PourmohamadrezaTajrishi M. [Speech Intelligibility in Children with Cochlear Implant, with Hearing Aids and Normal Hearing (Persian)]. Journal of Rehabilitation. 2013; 14(3):8-15.

[35] Jeddi Z, Jafari Z, Motasaddi Zarandy M. [The impact of cochlear implants and aural rehabilitation program on auditory skills of children with cochlear implant (Persian)]. Journal of Rehabilita-

tion. 2013; 14(1):61-70. 